\title{
UNMET SUPPORTIVE CARE NEEDS AMONG BONE SARCOMA PATIENTS IN SARAWAK
}

\author{
Cheah Whye Lian, Nurul B. Dollah, Chang C. Thon \\ Faculty of Medicine and Health Sciences, Universiti Malaysia Sarawak, Sarawak, Malaysia \\ Received: 25 November 2018 / Accepted: 23 December 2018
}

\begin{abstract}
Purpose: This study aimed to determine the prevalence of unmet supportive care needs among bone sarcoma patients in Kuching, Sarawak, and explored the relationship between these needs with various associated factors.

Methods: It was a descriptive cross-sectional study conducted among all bone sarcoma patients recruited from Sarawak General Hospital in Kuching, Sarawak. Data collection was done using an adopted questionnaire through interview-assisted survey. Unmet needs were assessed using the 59-item supportive care needs survey-SF59. Data were entered and analysed using SPSS version 20.

Results: A total of 75 respondents participated in the study. The patients were mainly $>36$ years $(56 \%)$, Sarawak natives (33.3\%), and married (54.7\%). Majority of patients were not undergoing any active treatment (52\%). Nine of 10 items with highest "moderate" to "high" level unmet needs were from the domain of health system and information. Needs from physical and daily living and sexuality domains were found to have statistically significant associations with ethnicity, age, and marital status.

Conclusion: Patients who were diagnosed with bone sarcoma had substantive unmet supportive care needs in relation with their illness trajectory. It is important that such needs to be acknowledged to provide quality health-care services to them.
\end{abstract}

Key words: Bone sarcoma, Malaysia, supportive care needs, supportive care needs survey-SF59, unmet needs

\section{Introduction}

Cancer is one of the chronic illnesses which cause major morbidity and mortality throughout the world. ${ }^{[1]}$ In Malaysia, approximately 70,000 new cases were diagnosed with cancer in between 2003 and 2005. ${ }^{[2]}$ Among the types of cancer, bone sarcoma accounts to about $5.3 \%$ of adults' malignancies in Malaysia. ${ }^{[3]}$ According to Solooki et al.,${ }^{[4]}$ bone sarcoma is one of rare cancer groups with incident rate of primary bone tumour comprises $0.2-0.5 \%$ of all malignancies. Incident rate for primary bone tumour is about 9 in 1 million per year.

The survival rate for bone tumour patient has improved remarkably with the advancement of various forms of surgical technique and chemotherapy treatment. ${ }^{[5]}$

Correspondence: Cheah Whye Lian, The Faculty of Medicine and Health Sciences, Universiti Malaysia Sarawak, Sarawak, Malaysia.

Email:wlcheah@unimas.my
Nevertheless, cancer patients still require supportive care services for symptoms control, nutritional advice, psychological, and other care, particularly from the healthcare providers. ${ }^{[6]}$ These services are pertinent because $16-45 \%$ of cancer patients were reported to have high level of anxiety, depression, and psychiatric disorder. ${ }^{[7]}$ In addition, various phases in cancer treatment could lead to physical distress and some could be life threatening. ${ }^{8]}$ Situation as such could also bring psychological impacts to the patients.

Studies had shown that supportive care should become a prominent aspect of cancer treatment and care as patients who were diagnosed with cancer faced difficulties in managing their daily activities, emotional breakdown, and other related issues..$^{[9,10]}$ They need to be assisted to manage these challenges. It was also reported that patients often complained of unmet needs related to psychological, interpersonal, health policy, health information, and 
physical aspect of daily activities. ${ }^{[6,11]}$ Some studies highlighted that the unmet needs of supportive care varied according to the type of cancer, treatment process, and management. ${ }^{[6]}$ Thus, a supportive care needs assessment that encompasses quality of life, physical functioning, as well as financial support of patients ${ }^{[9]}$ is an important component of cancer supportive care.

This study was conducted to assess the unmet needs of supportive care among bone sarcoma patients and its relationship with sociodemographic and health profile of the respondents. The outcome of this study is expected to provide information on how to improve the present care provision where supportive care has yet to be emphasised in the treatment of bone sarcoma patients.

\section{Methods}

This was a descriptive cross-sectional study using a need assessment tools explicitly assessed the gap between patient's experience of services they received and the extent to which their needs had been met. The study was carried out from 2015 to 2017, where the process of recruitment took 9 months and interview was carried out for another 6 months. Data were collected using face-to-face interview by the researchers based on the questionnaire from supportive care needs survey (SCNS)-59, the long version of SCNS tool assessment questionnaires adapted from Fisher et al. ${ }^{[1]}$ Interview was done as majority of the respondents were illiterate.

Sarawak General Hospital is a government hospital located at Kuching city which serves as special treatment facilities for patients from Sarawak, Sabah, Wilayah Persekutuan Labuan, as well as Indonesia. It is the only hospital that provides chemotherapy and radiotherapy for bone cancer patients, with two functional wards that have a bed strength for 72 patients. All patients diagnosed with bone sarcoma and receiving treatment at the Sarawak General Hospital were invited to participate in this study.

This study used a questionnaire that consists of sociodemographic data of respondents which included age, gender, race and marital status, health profile of respondents ( $1^{\text {st }}$ time diagnosed with bone sarcoma and the primary site of cancer), and treatment characteristics. The last section of the questionnaire consisted of supportive care needs (SCNS long version-59. SCNS is divided into five subscales of needs that patient may have as a result of the cancer: (1) Psychology needs related to emotional and coping (22 items); (2) health system and information needs related to the treatment centre and obtaining information about the disease, diagnosis, treatment, and follow-up (15 items); (3) physical and daily living needs related to coping with physical symptoms and side effects of treatments and performing daily physical tasks and activities ( 7 items); (4) patient care and support needs related to health-care providers showing sensitivity to physical and emotional needs, privacy, and choices (8 items); and (5) sexuality needs related to sexual relationship (3 items). Each of the question is scored on five-point scales: (1) No need - not applicable, (2) no need - satisfied, (3) low need, (4) moderate need, and (5) high need. Mean score was calculated by totaling the responses for each of the domains and dividing the total scores by the number of items in that domain. The scores were then dichotomised using the score of 0 for "no need" and equal and more than one for "some need." In this study, additional four questions adapted from Bonevski et al. ${ }^{[12]}$ related to specifically the need for ready access to services and resources such as transportation, counselling services, information, and financial assistance were added. Each item is preceded with a stem question, "talking to other people about the cancer," "changes in other people's attitudes and behavior toward cancer patient," "concerns about financial situation," and "concern about getting to and from the hospital."

Ethical approval was obtained from national medical research registry. Patients were briefed before the interview and consent forms were signed. Respondents were informed that their participation was voluntary and they could withdraw from the study if needed. They were also ensured of confidentiality of the data. The data collected were coded and entered using SPSS version 20. Data were analysed for frequency, means, and percentage and univariate analysis where appropriate.

\section{Results}

A total of 75 respondents participated in the study. The social demographic, health profile, and treatment characteristics of the respondents are presented in Table $1 \mathrm{a}$ and $\mathrm{b}$. Approximately $56 \%$ of the respondents 
Table 1a: Social demographic information characteristic, health profile, and treatment characteristic of respondent $(n=75)$

\begin{tabular}{|c|c|}
\hline Demographics & Frequency $(n)(\%)$ \\
\hline \multicolumn{2}{|l|}{ Age } \\
\hline $16-20$ years & $8(10.7)$ \\
\hline $21-25$ years & $15(20.0)$ \\
\hline $26-30$ years & $4(5.3)$ \\
\hline $31-35$ years & $6(8.0)$ \\
\hline$>36$ years & $42(56.0)$ \\
\hline \multicolumn{2}{|l|}{ Gender } \\
\hline Male & $35(46.7)$ \\
\hline Female & $40(53.3)$ \\
\hline \multicolumn{2}{|l|}{ Ethnic group } \\
\hline Sarawak's Bumiputera & $25(33.3)$ \\
\hline Malay & $22(29.3)$ \\
\hline Chinese & $14(18.7)$ \\
\hline Sabah's Bumiputera & $14(18.7)$ \\
\hline \multicolumn{2}{|l|}{ Marital status } \\
\hline Single & $34(45.3)$ \\
\hline Married & $41(54.7)$ \\
\hline \multicolumn{2}{|l|}{ First diagnosis } \\
\hline Within the past month & $9(12.0)$ \\
\hline $1-12$ months & $14(18.7)$ \\
\hline$>1-5$ years & $51(68.0)$ \\
\hline$>5$ years & $1(1.3)$ \\
\hline \multicolumn{2}{|l|}{ Primary cancer site } \\
\hline Proximal femur & $21(28.0)$ \\
\hline Proximal tibia & $17(22.7)$ \\
\hline Distal tibia & $10(13.3)$ \\
\hline Distal femur & $6(8.0)$ \\
\hline Right humerus & $6(8.0)$ \\
\hline Pelvic region & $4(5.3)$ \\
\hline Lumbar spine & $3(4.0)$ \\
\hline Left humerus & $2(2.7)$ \\
\hline Gluteal region & $2(2.7)$ \\
\hline Right axillary & $2(2.7)$ \\
\hline Right wrist & $1(1.3)$ \\
\hline Left scapula & $1(1.3)$ \\
\hline
\end{tabular}

were 36 years and older. More than one-third of the respondents are native of Sarawak (33\%). They were more married respondents (54.7\%) as compared to those who were single. A total of 51 respondents had been treated within 1-5 year's periods after having being diagnosed
Table 1b: Treatment characteristic of respondent $(n=75)$

\begin{tabular}{|c|c|}
\hline $\begin{array}{l}\text { Type of treatment ever } \\
\text { received }\end{array}$ & Frequency $(n)(\%)$ \\
\hline Chemotherapy & $7(9.3)$ \\
\hline Surgical removal of cancer & $12(16)$ \\
\hline Radiotherapy & $11(14.7)$ \\
\hline $\begin{array}{l}\text { Chemotherapy and surgical } \\
\text { resection }\end{array}$ & $15(20)$ \\
\hline $\begin{array}{l}\text { Chemotherapy and radiotherapy } \\
\text { treatment }\end{array}$ & $3(4)$ \\
\hline $\begin{array}{l}\text { Radiotherapy and surgical resec- } \\
\text { tion }\end{array}$ & $6(8)$ \\
\hline $\begin{array}{l}\text { Chemotherapy, radiotherapy, and } \\
\text { surgical removal }\end{array}$ & $21(28)$ \\
\hline \multicolumn{2}{|l|}{$\begin{array}{l}\text { Treatment received within the } \\
\text { past month }\end{array}$} \\
\hline No treatment & $55(73.3)$ \\
\hline Chemotherapy & $7(9.3)$ \\
\hline Surgery & $5(6.7)$ \\
\hline Radiotherapy & $5(6.7)$ \\
\hline Hormone treatment & $2(2.7)$ \\
\hline Multiple treatment & $1(1.3)$ \\
\hline \multicolumn{2}{|l|}{ Last admission for treatment } \\
\hline Within past month & $4(5.3)$ \\
\hline $1-12$ months & $39(52)$ \\
\hline $1-2$ years & $17(22.7)$ \\
\hline$>2$ years ago & $13(17.3)$ \\
\hline Never/cannot remember & $2(2.7)$ \\
\hline
\end{tabular}

with the disease. Nine respondents were diagnosed with cancer within the past month compared to 14 respondents who were diagnosed within 1-12 month's periods interval. The proximal femur bone was the highest site for sarcoma (28\%) followed by proximal tibia (22.7\%) and distal tibia $(10 \%)$.

Nearly a quarter of respondents (28\%) received the combination of chemotherapy, radiotherapy, and surgical intervention. This is followed by radiotherapy (20\%), surgical removal (16\%), radiotherapy (16.7\%), chemotherapy $(9.3 \%)$, and radiotherapy and surgical removal $(8 \%) .>70 \%(73.3 \%, n=55)$ of the respondents received no treatment within the past month. More than half $(52 \%)$ of the respondents were admitted for treatment within the 1-12 months period. 
Table 2 presents the 10 most frequently reported unmet supportive care needs which are under the category of "moderate and highest." Of 10 variables listed in the table, it showed that nine of the highest unmet need items were related to health system and only one item was related to the psychological need. All respondents reported that "to be adequate informed about the benefits and side effects of treatments before you choose to have them" was their "moderate or highest" unmet need. Of the 10 top "moderate and highest" unmet needs, $88.0 \%$ of the respondents had reported of "fears about the cancer spreading" in the psychological needs domain.

Table 3 shows the 10 lowest unmet needs, where six items in the table were from the domain of "physical and daily living."
Table 4 presents the SCNS profiles of the respondents by domain. Table 5 presents the statistical analysis on the relationship between SCNS and sociodemographic profile of the bone sarcoma patients. There were no significant differences in the mean score for all domains related to gender. In terms of races, Sarawak's Bumiputera has significant higher mean score than Sabah's Bumiputera $(P=0.008)$ in the physical and daily living domain. Apart from that, sexuality related to race showed that the mean score for Chinese was higher than Sarawak's Bumiputera $(P=0.04)$. Meanwhile, the mean score for respondents aged 36 years and more in physical daily living domain was significantly higher than those $<36$ years $(P=0.001)$. In term the sexuality domain, patients aged $<36$ years had higher mean score than those older than 36 years $(P=0.001)$. The mean score for physical and daily living

Table 2: 10 highest "moderate to high" level of unmet supportive care needs

\begin{tabular}{l|c|l}
\hline Type & Percentage & Domain \\
\hline $\begin{array}{l}\text { To be adequate informed about the benefits and side effects of treatments } \\
\text { before you choose to have them }\end{array}$ & 100 & Health system \\
\hline To be informed about your tests result as soon as possible & 98.7 & Health system \\
\hline To be informed about cancer that is under control or diminishing & 98.7 & Health system \\
\hline To be given explanation of those test for which you would like experience & 98.7 & Health system \\
\hline $\begin{array}{l}\text { The opportunity to talk to someone who understands and has been through a } \\
\text { similar experience }\end{array}$ & 96.0 & Health system \\
\hline To be given written information about the important aspect of care & 94.7 & Health system \\
\hline To be informed about things you can do to help yourself get well & 94.7 & Health system \\
\hline $\begin{array}{l}\text { To have one member of hospital staff with whom you can talk to about all } \\
\text { aspect of your conditions, treatment }\end{array}$ & 90.3 & Health system \\
\hline To be given choices about when you go in for test or treatment & 89.4 & Health system \\
\hline Fears about the cancer spreading & 88.0 & Psychological needs \\
\hline
\end{tabular}

Table 3: 10 lowest "moderate to highest" level of unmet supportive care needs

\begin{tabular}{l|c|l}
\hline Type & Percentage & Domains \\
\hline Physical and daily living - not being able to do the things you used to do & 30.0 & Physical and daily living \\
\hline More choice about which hospital you attend & 29.4 & Patient care and support \\
\hline More choice about which cancer specialist you see & 28.0 & Patient care and support \\
\hline Physical and daily living - work around home & 26.6 & Physical and daily living \\
\hline Feeling bored and/or useless & 24.0 & Psychological needs \\
\hline Physical and daily living - not sleeping well & 24.0 & Physical and daily living \\
\hline More fully protected rights to privacy when you are at the hospital & 22.7 & Patient care and support \\
\hline Physical and daily living - feeling unwell & 22.6 & Physical and daily living \\
\hline
\end{tabular}


Table 4: SNCS profile by domain $(n=75)$

\begin{tabular}{l|c}
\hline Domain & Mean \pm SD \\
\hline Psychological (22 items) & $3.57 \pm 0.431$ \\
\hline Highest: Worry about the result of treatment is beyond your control & $4.53 \pm 0.777$ \\
\hline Lowest: Feeling bored and/or useless & $3.17 \pm 0.876$ \\
\hline Health system and information (15 items) & $4.42 \pm 0.368$ \\
\hline Highest: To be informed about your tests result as soon as possible & $4.84 \pm 0.369$ \\
\hline Lowest: Hospital staff to convey a sense of hope to you and your family & $3.91 \pm 0.661$ \\
\hline Physical and daily living (7 items) & $2.38 \pm 0.829$ \\
\hline Highest: Not being able to do the things you used to do & $2.99 \pm 1.145$ \\
\hline Lowest: Pain & $0.93 \pm 0.251$ \\
\hline Patient care and support (8 items) & $3.34 \pm 0.520$ \\
\hline Highest: Waiting a long time for clinic appointment & $3.77 \pm 0.924$ \\
\hline Lowest: More choice about which cancer specialist you see & $2.75 \pm 1.253$ \\
\hline Sexuality (3 items) & $2.73 \pm 0.829$ \\
\hline Highest: Changes in sexual relationship & $3.63 \pm 0.818$ \\
\hline Lowest: To be given information about sexual relationship & $0.97 \pm 0.162$ \\
\hline
\end{tabular}

SD: Standard deviation

Table 5: Mean score of SCNS by sociodemographic profile $(n=75)$

\begin{tabular}{|c|c|c|c|c|c|}
\hline \multicolumn{6}{|c|}{ Adjusted mean (95\% CI) } \\
\hline & $\begin{array}{c}\text { Psychological } \\
\text { needs }\end{array}$ & Health system & $\begin{array}{c}\text { Physical and } \\
\text { daily living }\end{array}$ & $\begin{array}{l}\text { Patient care } \\
\text { and support }\end{array}$ & Sexuality \\
\hline \multicolumn{6}{|l|}{ Gender } \\
\hline Male & $3.76(3.61,3.91)$ & $4.46(4.35,4.58)$ & $2.52(2.23,2.81)$ & $3.45(3.28,3.63)$ & $2.85(2.66,3.03)$ \\
\hline Female & $3.71(3.56,3.86)$ & $4.38(4.26,4.51)$ & $2.26(2.00,2.51)$ & $3.24(3.08,3.41)$ & $2.63(2.46,2.81)$ \\
\hline$P$-value & 0.621 & 0.354 & 0.175 & 0.077 & 0.091 \\
\hline \multicolumn{6}{|l|}{ Ethnic group ${ }^{b}$} \\
\hline Malay & $3.76(3.58,3.95)$ & $4.48(4.38,4.59)$ & $2.19(1.86,2.52)$ & $3.28(3.04,3.53)$ & $3.00(2.80,3.20)$ \\
\hline Chinese & $3.74(3.47,4.01)$ & $4.40(4.21,4.60)$ & $2.74(2.22,3.27)$ & $3.56(3.27,3.86)$ & $2.88(2.55,3.22)$ \\
\hline Sarawak Bumiputera & $3.80(3.60,4.01)$ & $4.34(4.15,4.54)$ & $2.66(2.36,2.96)$ & $3.32(3.11,3.52)$ & $2.41(2.19,2.64)$ \\
\hline Sabah Bumiputera & $3.56(3.34,3.78)$ & $4.48(4.26,4.69)$ & $1.81(1.39,2.22)$ & $3.25(2.96,3.54)$ & $2.74(2.52,2.95)$ \\
\hline$P$-value & 0.44 & 0.574 & $0.002^{c}$ & 0.353 & $0.001^{d}$ \\
\hline \multicolumn{6}{|l|}{$\operatorname{Age}^{a}$} \\
\hline 36 years and below & $3.70(3.54,3.86)$ & $4.47(4.37,4.57)$ & $2.02(1.78,2.26)$ & $3.34(3.16,3.52)$ & $2.97(2.82,3.12)$ \\
\hline$>36$ years & $3.76(3.62,3.90)$ & $4.38(4.25,4.51)$ & $2.66(2.40,2.92)$ & $3.34(3.18,3.51)$ & $2.55(2.37,2.73)$ \\
\hline$P$-value & 0.572 & 0.318 & 0.001 & 0.966 & 0.001 \\
\hline \multicolumn{6}{|l|}{ Marital status ${ }^{a}$} \\
\hline Single & $3.66(3.53,3.79)$ & $4.42(4.30,4.54)$ & $2.06(1.85,2.28)$ & $3.35(3.18,3.53)$ & $2.77(2.59,2.96)$ \\
\hline Married & $3.80(3.64,3.95)$ & $4.42(4.29,4.54)$ & $2.64(2.36,2.92)$ & $3.33(3.16,3.50)$ & $2.70(2.52,2.87)$ \\
\hline$P$-value & 0.197 & 0.981 & 0.002 & 0.846 & 0.557 \\
\hline
\end{tabular}

aindependent $t$-test: $P<0.05$, 'D One-way ANOVA: Post hoc test, 'Sarawak Bumiputera versus Sabah Bumiputera: $P=0.008$; Sabah Bumiputera versus Chinese, $P=0.011$, dMalay versus Sarawak Bumiputera: $P=0.001$; Chinese versus Sarawak Bumiputera, $P=0.04$ 
domain was found to higher among the married respondents compared to those who were single $(P=0.002)$.

\section{Discussion}

This cross-sectional study using SCNS tool aimed to identify the bone sarcoma patients' unmet needs in Sarawak General Hospital. There were 75 respondents participated in this study, with $>50 \%$ of them aged 36 years and above, female, Sarawak natives, and married. The age group, sex, ethnicity, and marital status profiles were consistent with an earlier study carried out among the same cancer group in the same hospital. ${ }^{[13]}$

The findings also show that about $68 \%$ of the respondents were diagnosed after 1-5 years of their symptoms, indicated a delay in diagnosis that can be due to many reasons. Tumours can be misdiagnosed, missed, or mistreated due to the symptoms mimic those of common sprains, strains, bumps, and bruises. ${ }^{[14]}$ Therefore, it is important that a group of multidisciplinary experts work together to reduce the numbers of missed diagnosis. The top three common sites of bone tumour were proximal femur, proximal tibia, and distal tibia, with the most common treatment included chemotherapy, radiotherapy, and surgical removal. The post-treatment period (based on the last admission for treatment and type of treatment received by the respondents) was similar to other studies. ${ }^{[15,16]}$

In terms of unmet needs, the top three domains that had the highest mean score were health system and information domain (mean score 4.42, standard deviation [SD] 0.368), psychological domain (mean score 3.57, SD 0.431), and patient care and support domain (mean score 3.34, SD 0.520). Meanwhile, physical and daily living domain had the lowest with mean score of 2.38 (SD 0.829). As there is no reference pertaining to bone cancer specifically, the comparison here was done with other types of cancer. Most cancer studies reported the same findings where health system and information domain were ranked the highest unmet need among all domains. ${ }^{[11,16,17]}$ This finding indicated that cancer patients were not satisfied with the information received during treatment. It would be more helpful to them if information is obtained earlier at the time when confirmed diagnosis was delivered, which will help them to cope better. On the other hand, the patients might not be given a good health-care support system that helped them to cope. Could it be because the breaking of news was abrupt and there was no follow-up discussion on care when patients were ready? Support of psychologist at the hospital setting is not common as it is not under the treatment protocol during the study. Evidence from literature showed that patients valued the importance of "relational" aspects of care where they want their dignity to be protected and be respected. ${ }^{[18]}$ Thus, it is important that the health-care professionals to acknowledge patients' individuality and the uniqueness of experience and its impact on their life to provide appropriate.

This study found that nine of 10 items with highest "moderate" to "high" level unmet needs were from the health system and information domain. The highest of them was "to be adequate informed about the benefits and side effects of treatment before you choose to have them," followed by "to be informed about your test results as soon as possible." This showed that the information regarding their illness was not properly communicated it was done inadequately. One possible reason was that the supportive environment for attending to patients was lacking with over-crowded clinic area. A good communication can facilitate early diagnosis, improve self-management, and reduce inequalities in access of care. It is also critical in empowering patients to know more about their illness to make the right decision. By providing a wide range of information and support, cancer patients are less likely to seek information from unreliable sources that can cause more stress to both the patients themselves as well as health-care providers. ${ }^{[19]}$

In general, all except for item "Fear about the cancer spreading," under psychological domain was rated to be of "some need." This finding contradicted the literature where psychological domain was ranked to be the highest unmet needs, particularly among western countries. ${ }^{[1,6,20]}$ Such differences could be due to cultural differences. Like any Asian countries, Malaysians still maintain a strong traditional family structure where family usually provides needed support to facilitate patients' adaptation process.

Respondents who aged 36 years or younger reported to have significant higher unmet needs in sexuality. This finding is congruent with a study by Fisher et al. ${ }^{[1]}$ where younger cancer patients were more vocal of their sexual needs than older patients. Malay and Chinese 
had significant higher mean score in sexuality domain compared to Sarawak Bumiputera $(P=0.001, P=0.04)$. Further, analysis indicated that majority of the Malay and Chinese respondents were younger. Older respondents had significant higher unmet needs in physical and daily living due to aging process.

There may be an element of cultural background and variation in health beliefs which influence the level of needs in these domains. Further, exploration into this area is needed to understand these variations.

In terms of ethnicity, significant higher unmet need was found in physical and daily living among Sarawak Bumiputera and Chinese compared to Sabah Bumiputera $(P=0.08, P=0.011)$. Analysis at the ethnicity and age group indicated that there were older Sarawak Bumiputera and Chinese respondents compared to Sabah Bumiputera. There may be elements of sociocultural background and variation in health practices which influence the different in unmet needs. More studies are needed to understand these differences. Nevertheless, it is important to acknowledge older cancer patient in this study was set at $>35$ years of age where they are still physically active, but in terms of biological and physiological well-being, they might not as good as their younger counterpart. This is evidenced by higher significant unmet needs in 'physical and daily living' was found among older respondents. Higher level of unmet needs in physical and daily living domain was found among respondents who are married compared to those who are single $(P=0.02)$. A study by Zebrack $^{[21]}$ indicated that married patients had greater responsibilities toward their family members and their own health.

\section{Conclusion}

The current study provides the first evidence of the prevalence of supportive care needs for bone sarcoma patients in a public hospital in Sarawak. Overall, the highest levels of unmet needs were found within the health system and information domain. However, older respondents (36 years and above), married and certain ethnic groups (can you be specific here, which race?) significant higher levels of unmet needs in the physical and daily living domain. Significant higher level of unmet needs in sexuality was found among younger age group.
This was a cross-sectional study; thus, the cause-effect relationship could not be determined. Furthermore, any response bias was unavoidable due to response type of data collection. Nevertheless, this study provides an insight on the patients' perceived unmet needs as a result of their cancer. It is important for health-care providers to address those areas of unmet needs, in particular in the delivery of health system and information to improve their health-care delivery, and further facilitates bone sarcoma patients in all stages of their treatment.

\section{Conflict of Interest}

The authors declare that they have no conflict of interest.

\section{References}

1. Fisher RS, Girgis A, Boyes A, et al. The unmet supportive care needs of patients with cancer. Cancer 2000;88:226-37.

2. Hassan MR, Lim W, editors. The First Annual Report of the National Cancer Patient Registry-Colorectal Cancer, 2007-2008, Kuala Lumpur, Malaysia; 2010.

3. National Cancer Registry. Malaysian Cancer Statistics - Data and Figure Peninsular Malaysia 2006. Ministry of Health Malaysia, Kuala Lumpur, Malaysia; 2006.

4. Solooki S, Vosoughi AR, Masoomi V. Epidemiology of musculoskeletal tumors in shiraz, south of Iran. Indian J Med Paediatr Oncol 2011;32:187-91.

5. van Dam MS, Kok GJ, Munneke M, et al. Measuring physical activity in patients after surgery for a malignant tumour in the leg. The reliability and validity of a continuous ambulatory activity monitor. J Bone Joint Surg Br 2001;83:1015-9.

6. Boyes A W, Girgis A, D'Este C, et al. Prevalence and correlates of cancer survivors supportive care needs 6 months after diagnosis: A population - based cross- sectional study. BMC Cancer 2012;12:150.

7. Pigott C, Pollard A, Thomson K, et al. Unmet needs in cancer patients: Development of a supportive needs screening tool (SNST). Support Care Cancer 2009; 17:33-45.

8. Adler NE, Ann EK. Cancer Care for the Whole Patient. Meeting Psychosocial Health Need. Committee on Psychosocial Service to Cancer Patient/Families in Community Setting. Washington, DC. The National Academies Press; 2008. p. 23-4.

9. Harrison JD, Young JM, Price MA, et al. What are the unmet supportive care needs of people with cancer? A systematic review. Support Care Cancer 2009;17:1117-28.

10. Kash KM, Mago R, Kunkel EJ. Psychosocial oncology: Supportive care for the cancer patient. Semin Oncol 2005;32:211-8.

11. Park BW, Hwang SY. Unmet needs of breast cancer patients 
relatives to survival duration. Yonsei Med J 2012;53:118-25.

12. Bonevski B, Fisher RS, Girgis A, et al. Evaluation of an instrument to assess the needs of patients with cancer. Cancer 2000;88:217-24.

13. Cheah WL, Soh MH, Chang CT. Study on health-related quality of life among bone cancer patients. Austral - Asian J Cancer 2013;12:115-21.

14. Grimer RJ, Carter SR, Spooner D, et al. Diagnosing musculoskeletal tumours. Sarcoma 2001;5:89-94.

15. Hall AE, Boyes AW, Bowman J, et al. Young adult cancer survivors' psychosocial well-being: A cross-sectional study assessing quality of life, unmet needs, and health behaviors. Support Care Cancer 2012;20:1333-41.
16. Keegan TH, Lichtensztajn DY, Kent EE, et al. Unemet adolescent and young adult cancer survivors' information and services needs: A population-based cancer registry study. J Cancer Surviv 2012;6:239-50.

17. Armes J, Crowe M, Colbourne L, et al. Patients' supportive care needs beyond the end of cancer treatment: A prospective, longitudinal survey. J Clin Oncol 2009;27:6172-9.

18. Cohen J, Ezer T. Human rights in patient care: a theoretical and practical framework. Health Hum Rights 2013;15:7-19.

19. Balmer C. The information requirements of people with cancer: Where to go after the patient information leaflet? Cancer Nurs 2005;28:6-44.

20. Ream E, Quennell A, Fincham L, et al. Supportive care 